\title{
The role of the SOS response in bacteria exposed to zidovudine or trimethoprim
}

\author{
C. S. LEWIN and S. G. B. AMYES \\ Department of Bacteriology, University of Edinburgh Medical School, Teviot Place, Edinburgh EH8 9AG
}

\begin{abstract}
Summary. Trimethoprim was more potent than zidovudine as an inducer of the SOS response in Escherichia coli. The level of induction by each compound initially increased with rising drug concentration and then fell; this effect was less marked with zidovudine than with trimethoprim. The SOS response did not appear to be involved in the inhibition of bacterial multiplication as the MICs of trimethoprim or zidovudine for recA430 and lexA3 mutants, which are unable to induce the SOS response, were identical to the MICs for the parent strains. However, the bactericidal activity of each compound against strains deficient in the SOS response was reduced. This suggests that induction of the DNA repair system contributes to the bactericidal activity of the drugs.
\end{abstract}

\section{Introduction}

The SOS response, which assists bacteria to repair damage to DNA, is controlled by two regulatory proteins, the recA and lexA gene products. These proteins govern transcription of a subordinate group of genes coding for DNA repair enzymes and cell division inhibitors, the individual activities of which make up the SOS response. ${ }^{1}$ The lexA gene product functions as a repressor binding to similar operator sequences on the SOS genes, while the recA gene product provides a direct or indirect signal for induction of the SOS response. ${ }^{1}$ Treatment of bacteria with antibacterial agents such as the 4-quinolones, which damage DNA, leads to the induction of this DNA repair pathway. ${ }^{1-3}$

One consequence of induction of the SOS response is bacterial filamentation as one of the SOS genes, the $s f i A$ gene, codes for a protein that binds to the $s f B$ (ftsZ) gene product, which is essential for septation..$^{4-7}$ After the SOS response is switched off, the sfiA gene product is degraded by the lon (capR) protease and bacterial cell division resumes. ${ }^{7,8}$

Trimethoprim and zidovudine are synthetic compounds which inhibit bacterial DNA synthesis. ${ }^{9-11}$ Trimethoprim prevents incorporation of thymine into bacterial DNA by inhibition of dihydrofolate reductase. ${ }^{9}$ Zidovudine is a thymidine analogue in which the $3^{\prime}$ hydroxy group is replaced by an azido group; zidovudine is incorporated into bacterial DNA and the azido group makes subsequent $5^{\prime}-3$ ' phosphodiester linkages impossible. ${ }^{10}$ Bacteria exposed to each of these compounds undergo filamentation, ${ }^{9-11}$ suggesting that they may induce the SOS response. To

Received 21 June 1990; revised version accepted 27 Sep. 1990. investigate this, $\beta$-galactosidase activity was measured in a strain of Escherichia coli possessing a deletion of the lac operon and a sfiA: : flacZ operon fusion. The susceptibility to trimethoprim and zidovudine of bacteria deficient in the SOS response was also determined to establish whether the SOS DNA repair system was involved in the antibacterial activity of these drugs.

\section{Materials and methods}

\section{Antibacterial agents}

Trimethoprim lactate and zidovudine (Wellcome) were dissolved in sterile distilled water.

\section{Bacterial strains}

Six $E$. coli strains were used in this investigation; E. coli GC4415 thr leu his pyrD trp : : Mu $C^{+}$lac malB galK rpsL srl-300: : tnlO sfia: : Mudl (aplac) (obtained from Professor I. Phillips) and a zidovudine-resistant mutant of this strain, which was deficient in thymidine kinase; E. coli AB1157, F - thr-1 leu-6 proA2 his4 thi1 argE3 lacY1 galK2 ara-14 xyl-5 mtl-1 tsx-33 strA31 sup-37; E. coli AB2494, as strain AB1157 but also metb-1 pps-31 lexA3; E. coli SC1656, thr leu thi proA argE3 ilv $^{\text {ts }}$ galK sup-37 straA31 sfiB srlC $300 ;$ E. coli IC1657, as strain SC1656, but also recA430 (obtained from Professor J. T. Smith).

\section{Induction of the SOS response}

This was measured as previously described ${ }^{12}$ with the following modification: Nutrient Broth (Oxoid) 
was used instead of LB Broth as the growth medium for zidovudine tests whereas Iso-Sensitest Broth (Oxoid) was used for trimethoprim.

SOS induction was expressed as $\beta$-galactosidase activity in Miller Units ${ }^{12}$ derived by use of the formula:

$$
\frac{1000\left(\mathrm{OD}_{420}-1.75 \times \mathrm{OD}_{550}\right)}{\mathrm{t} \times \mathrm{v} \times \mathrm{OD}_{600}}
$$

where $\mathrm{OD}_{420}$ and $\mathrm{OD}_{550}$ were the optical densities at the relevant wavelength after $t \mathrm{~min}$; $\mathrm{v}$ was the reaction volume; and $\mathrm{OD}_{600}$ was the initial $\mathrm{OD}$ at $600 \mathrm{~nm}$.

\section{Minimum inhibitory concentrations (MICs)}

MICs were measured on nutrient agar for zidovudine and on Iso-Sensitest agar for trimethoprim with the arithmetic dilution scheme previously described. ${ }^{13}$ An inoculum of $10^{4}$ cfu per spot was used and the MIC was taken as the lowest concentration that inhibited visible growth after overnight incubation at $37^{\circ} \mathrm{C}$

\section{Bactericidal activity}

The bactericidal activities of zidovudine in nutrient broth and trimethoprim in Iso-Sensitest broth were measured by viable counting on nutrient agar as previously described. ${ }^{14}$

\section{Results}

Each of the test strains, with the exception of the zidovudine-resistant mutant of $E$. coli GC4415 (MIC of zidovudine $>500 \mathrm{mg} / \mathrm{L}$ ), was inhibited by trimethoprim or zidovudine at a concentration of $0.1 \mathrm{mg} / \mathrm{L}$.

Inhibitory concentrations of trimethoprim and zidovudine induced the SOS response in $E$. coli GC4415 after exposure for $1 \mathrm{~h}$ (fig. 1). The level of induction initially increased with rising drug concentration and then fell. The concentration at which maximum induction of the SOS response was achieved was about $5 \mathrm{mg} / \mathrm{L}$ with each drug. The induction of the SOS response caused by exposure to zidovudine was greater than that caused by exposure to trimethoprim, and the decline observed after the peak concentration was reached was more marked with trimethoprim than with zidovudine.

When thymidine $50 \mathrm{mg} / \mathrm{L}$ was added to Iso-Sensitest broth the SOS response was no longer induced by trimethoprim at concentrations up to $100 \mathrm{mg} / \mathrm{L}$. Zidovudine did not induce the SOS response in a zidovudine-resistant derivative of $E$. coli GC4415 which was deficient in thymidine kinase activity (fig. 1). A linear increase in the induction of the SOS response was observed over a 3-h period of exposure to zidovudine or trimethoprim $5 \mathrm{mg} / \mathrm{L}$; the level of induction achieved by trimethoprim was weaker than that observed with zidovudine (fig. 2).

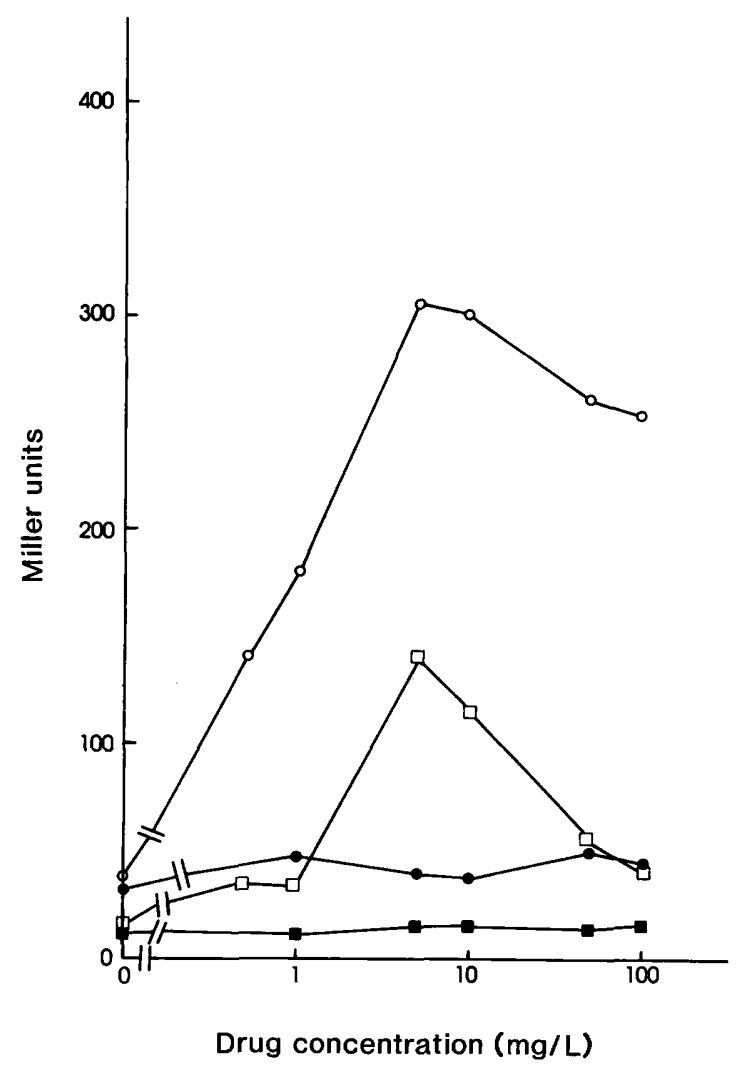

Fig. 1. Induction of SOS response in E. coli GC4415 exposed to trimethoprim $\square-\square$, trimethoprim + thymidine $50 \mathrm{mg} / \mathrm{L} \square-$ - $\square$ or zidovudine $\mathrm{O}-\mathrm{O}$, and in a zidovudine resistant derivative of $E$. coli $\mathrm{GC4415}$ exposed to zidovudine -- .

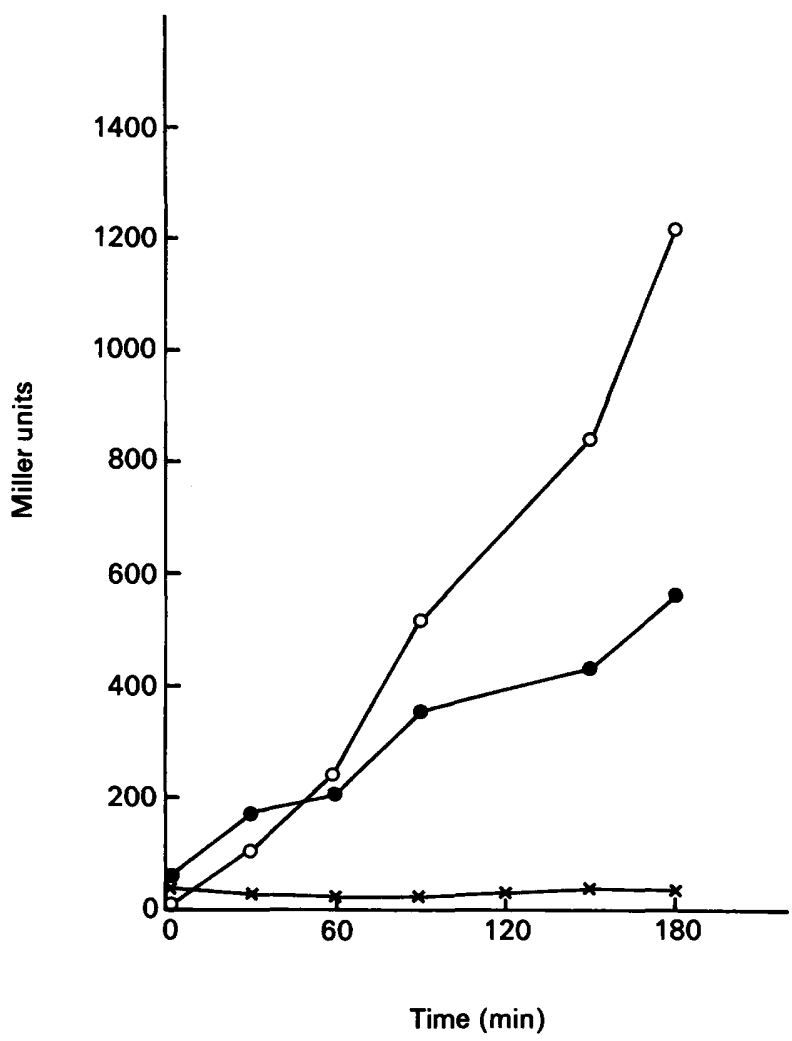

Fig. 2. Induction of the SOS response in $E$. coli GC441 5 exposed for $3 \mathrm{~h}$ at $37^{\circ} \mathrm{C}$ to trimethoprim $5 \mathrm{mg} / \mathrm{L}-$, zidovudine $5 \mathrm{mg} / \mathrm{L}$ $\mathrm{O}-\mathrm{O}$, or no drug $\mathrm{x}-\mathrm{x}$. 
After exposure for $3 \mathrm{~h}$ to inhibitory concentrations of trimethoprim or zidovudine, the bactericidal activity of either drug against a lexA3 mutant (unable to induce the SOS response because its lexA protein is resistant to proteolysis catalysed by the $\operatorname{rec} A$ gene product) was reduced in comparison to the effect on the parent strain $\mathrm{AB} 1157$ at all concentrations tested (fig. 3). Similarly, trimethoprim and zidovudine were less bactericidal against a rec $A 430$ mutant than against the parent strain SCl656 (fig. 4).

\section{Discussion}

The finding that inhibitory concentrations of zidovudine and trimethoprim induced the SOS response in E. coli is consistent with the observations that these compounds inhibit bacterial DNA synthesis (an event associated with SOS induction ${ }^{1}$ ) and cause filamentation. $^{9,11}$ Blockage of the replication fork by these drugs may trigger the DNA repair system, because the inhibition of dihydrofolate reductase by trimethoprim causes thymine starvation and stalling of the replication fork. ${ }^{9}$ In keeping with this the SOS response was no longer induced by trimethoprim in the presence of thymidine which antagonises the effect of trimethoprim by relieving the thymine starvation effect of the drug. Similarly zidovudine, which after phosphorylation by thymidine kinase causes DNA chain termination to occur, ${ }^{10}$ did not induce the SOS response in a zidovudine-resistant derivative of $E$. coli

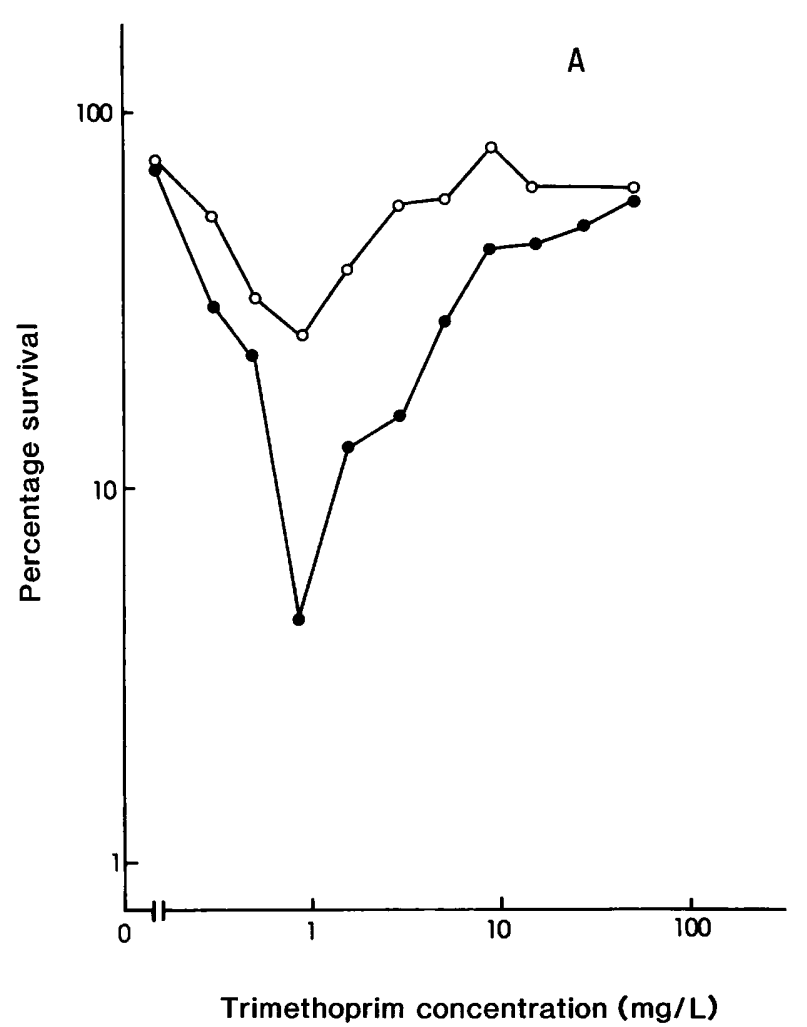

GC4415 lacking thymidine kinase activity. This mutant possesses an intact SOS repair system which is inducible by nalidixic acid (unpublished results). The fluctuation in the level of induction of the SOS response with rising drug concentration has also been observed with the 4-quinolones. ${ }^{2,3}$ Zidovudine was found to be a stronger inducer of the SOS response than trimethoprim, but both drugs appeared to be weaker inducers than the 4-quinolones ${ }^{2}$ (also C. S. Lewin, unpublished results).

The SOS response does not appear to play a role in the events leading to the inhibition of bacterial multiplication by either zidovudine or trimethoprim, as an inability to induce the DNA repair pathway had no effect on MICs of the drugs. However, induction of the SOS response seems to contribute to the lethality of the compounds as their bactericidal activities against $E$.coli strains unable to induce the SOS response were decreased. Hence, rather than repairing the damage caused by trimethoprim or zidovudine, the induction of the SOS response appears to contribute to their bactericidal activity; however, this is not the only event involved in the lethality of trimethoprim or zidovudine as the drugs were still bactericidal against these mutant strains.

Interestingly, induction of the SOS response by nalidixic acid does not seem to contribute to the lethality of that drug. ${ }^{14,15}$ Thus, although trimethoprim, zidovudine and nalidixic acid are similar in that

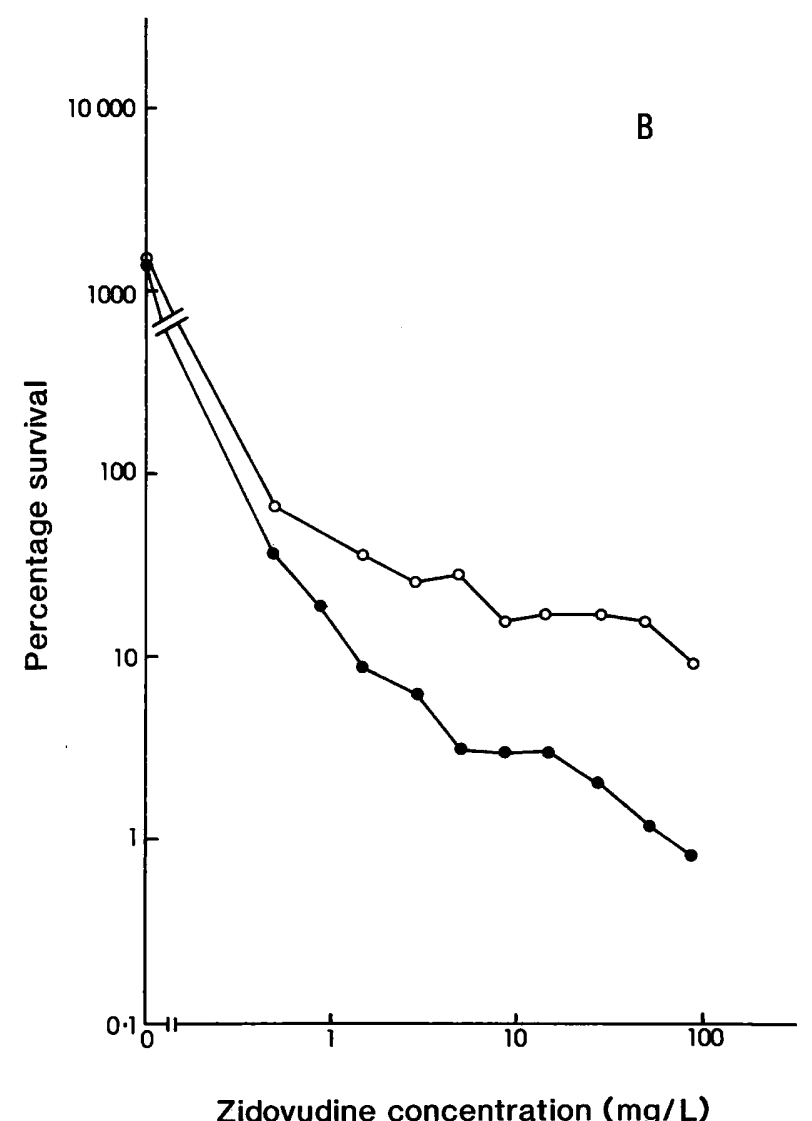

Fig. 3. Survival of $E$. coli strain AB1157 broth or (B) zidovudine in nutrient broth. 


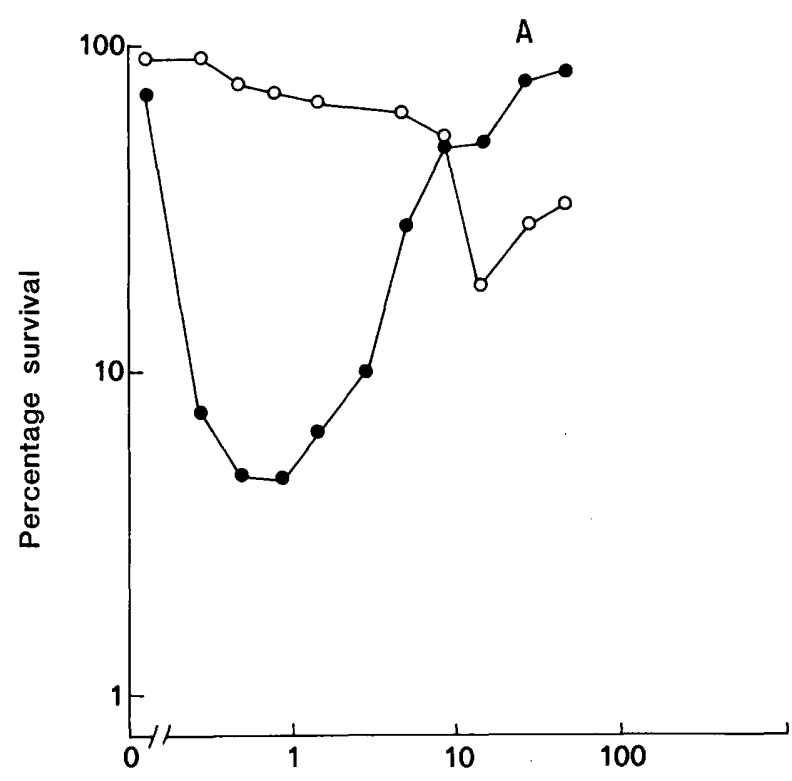

Trimethoprim concentration $(\mathrm{mg} / \mathrm{L})$

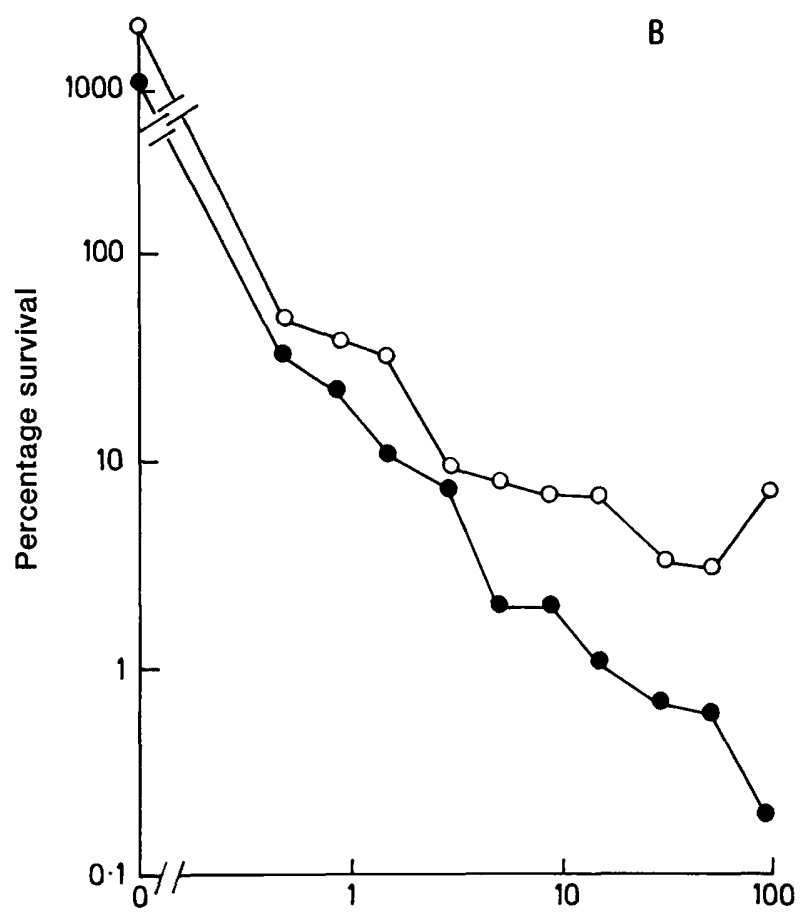

Zidovudine concentration $(\mathrm{mg} / \mathrm{L})$

Fig. 4. Survival of $E$. coli strains SC1656

broth or (B) zidovudine in nutrient broth

they inhibit DNA synthesis, induce the SOS response $^{1-3}$ and require protein synthesis for their lethality, $9,11,16$ the lethal consequences of damage to bacterial DNA by the 4-quinolone appear to be different. This may be linked to the observation that the bactericidal activity of the 4-quinolones is greater than those of trimethoprim or zidovudine (C. S. Lewin, unpublished results).

It has been suggested that drugs which induce the SOS response are potential bacterial mutagens ${ }^{2,17}$ because DNA repair is prone to error and mutations may be introduced into the bacterial chromosome.

\section{References}

1. Walker GC. Mutagenesis and inducible responses to deoxyribonucleic acid damage in Escherichia coli. Microbiol Rev $1984 ; 48$ : 60-93.

2. Phillips I, Culebras E, Moreno F, Baquero F. Induction of the SOS response by new 4-quinolones. J Antimicrob Chemother 1987; 20 : 631-638

3. Piddock LJV, Wise R. Induction of the SOS response in Escherichia coli by 4-quinolone antimicrobial agents. FEMS Microbiol Lett 1987; 41 : 289-294.

4. Huisman $O$, D'Ari R. An inducible DNA replication-cell division coupling mechanism in $E$. coli. Nature 1981; 290: 797-799.

5. Huisman O, D'Ari R, Gottesman S. Cell-division control in Escherichia coli: specific induction of the SOS function sfiA protein is sufficient to block septation. Proc Natl Acad Sci USA $1984 ; 81$ : $4490-4494$.

6. Lutkenhaus J, Sanjanwala B, Lowe M. Overproduction of FtsZ suppresses sensitivity of lon mutants to division inhibition. $J$ Bacteriol 1986; 166: 756-762.

7. Maguin E, Lutkenhaus J, D'Ari R. Reversibility of SOSassociated division inhibition in Escherichia coli. J Bacteriol 1986; 166: 733-738.

8. Mizusawa S, Gottesman S. Protein degradation in Escherichia
The possibility that zidovudine might act as a bacterial mutagen should be investigated because patients suffering from the Acquired Immune Deficiency Syndrome are susceptible to opportunist bacterial infections. A worrying scenario will emerge if exposure of bacteria to zidovudine increases the frequency at which bacteria are able to develop resistance to antibiotics.

We thank the Scottish Home and Health Department for financial support.

coli: the lon gene controls the stability of sulA protein. Proc Natl Acad Sci USA 1983; 80: 358-362.

9. Amyes SGB, Smith JT. Trimethoprim action and its analogy with thymine starvation. Antimicrob Agents Chemother $1974 ; 5: 169-178$.

10. Elwell LP, Ferone R, Freeman GA et al. Antibacterial activity and mechanism of action of $3^{\prime}$-azido-3'-deoxythymidine (BW A509U). Antimicrob Agents Chemother 1987; 31 : 274 280.

11. Lewin CS, Amyes SGB. Conditions required for the antibacterial activity of zidovudine. Eur J Clin Microbiol Infect Dis $1989 ; 8$ : 737-741.

12. Miller JH. Experiments in molecular genetics. Cold Spring Harbor, NY, Cold Spring Harbor Laboratory. 1972.

13. Smith JT. Mutational resistance to the 4-quinolone antibacterial agents. Eur J Clin Microbiol 1984; 3: 347-350.

14. Lewin CS, Howard BMA, Ratcliffe NT, Smith JT. 4-quinolones and the SOS response. J ḾR Microbiol 1989; 29: 139-144.

15. McDaniel LS, Rogers LH, Hill WE. Survival of recombinationdeficient mutants of Escherichia coli during incubation with nalidixic acid. J Bacteriol 1978; 134 : 1195-1198.

16. Deitz WH, Cook TM, Goss WA. Mechanism of action of nalidixic acid on Escherichia coli. III Conditions required for lethality. $J$ Bacteriol $1966 ; 91$ : 768-773.

17. Phillips I. Bacterial mutagenicity and the 4-quinolones. $J$ Antimicrob Chemother 1987; 20: 771-772. 